\title{
Reform of Practice Teaching System of Measurement \& Control Technology and Instrument Based on CDIO Engineering Education Model
}

\author{
Jincai Zhao ${ }^{1, *}$, Guoyan $\mathrm{Liu}^{1}$, Yong $\mathrm{Wei}^{1}$, Yanan Zeng ${ }^{1}$ and Haiyun $\mathrm{Wu}^{1}$ \\ ${ }^{1}$ College of Technology, Tianjin Agricultural University, Tianjin 300384, China \\ *Corresponding author.Email: jincai.zhao@qq.com
}

\begin{abstract}
In order to improve students' engineering practice ability, innovation awareness and teamwork awareness, and the quality of application-oriented talent training, combined with the core concept of engineering education professional certification, the teachers in Measurement \& Control Technology and Instrument of Tianjin Agricultural University have carried out some reforms in the construction of professional practice. Based on the relevant annotations of engineering education professional certification and guided by CDIO engineering education thought, the thesis has analyzed the status quo and existing problems of professional practice teaching. It focuses on the content of curriculum design, quality monitoring of curriculum design process, "Internet + practical teaching" and other aspects. It actively explores the professional construction of measurement and control and student-centered practical teaching methods and approaches.
\end{abstract}

Keywords: CDIO Engineering Education Model; Practice Teaching System; Innovation; Teamwork

\section{INTRODUCTION}

The measurement \& control technology and instrument major of our school is affiliated to the Department of Automation Engineering, College of Engineering and Technology, Tianjin Agricultural University. The major began to recruit students in 2005 , and was approved as an application-oriented major in Tianjin colleges and universities in 2017. It aims at the needs of Rural Revitalization and social and regional economic development, and trains talents who can be engaged in testing and control, design and development of instrument and instrument system, application of optical and electronic control engineering, quality control, quality control, quality control and management of production process, product technical support, etc. in the fields of agricultural intelligent equipment research and development, intelligent agricultural application, environment and agricultural product safety. At the same time, these talents should have strong practical ability and innovative consciousness, and be able to meet the needs of the development of modern urban agriculture. The specialty of measurement and control technology and instrument has the advantages of wide knowledge, interdisciplinary and comprehensive. Practical teaching is an important part of teaching work, a pivotal link in deepening classroom teaching and an indispensable way for students to acquire and master knowledge. And it is of the proper meaning in cultivating high-quality top-notch talents[1]. Under the background that universities are actively participating in the international engineering education professional certification, how to further improve the engineering practice ability of students and optimize the practical teaching system is the primary problem that needs to be solved urgently[2,3].

\section{CURRENT SITUATION AND ANALYSIS OF PRACTICE TEACHING}

After nearly 20 years of construction and development, the measurement \& control technology and instrument in our university has established a relatively complete teaching system and training plan. However, judging from the current teaching situation, the performance and development of students after graduation, there is still greater room for improvement. After investigation and discussions with some graduates working in different industries, it reflects that the talents trained by my major have good unilateral practical ability. However, there is much room for improvement in the ability to analyze and solve complex engineering problems; the ability to innovate is insufficient, and the awareness and willingness to innovate are not strong; the abilities of students are uneven, which does not meet the requirements of engineering certification for full coverage of student training ability evaluation. The reasons mainly exist in the following aspects:

(1) The Measurement \& Control Technology and Instrument has a strong practicality. The engineering practice ability of students plays an important role in the talent training process. Although there are four professional curriculum design links in the training program, the content of the four-curriculum design is relatively independent, it 
fails to form a complete process. From a student's perspective, it cannot be effective and coherent to form an understanding and cognition of complex engineering problems.

(2) In the course of curriculum design and implementation, the quality of practical ability training is insufficient. Traditional methods are generally used to complete prescribed actions according to the syllabus, and they lack the awareness of effectively motivating or promoting students' innovation.

(3) The supervision mechanism and process control of practical teaching are not sound enough, and some students are not enthusiastic about participating, which seriously hinders the achievement of the element of "all students" in engineering certification.

\section{REFORM OF THE PRACTICAL TEACHING SYSTEM}

Practice is the characteristic and soul of the teaching of measurement and control specialty. Constructing a scientific and practical teaching training system that meets the requirements of engineering education plays a vital role in the training quality of measurement and control students. The concept and model of CDIO engineering education is funded by the Knut and Alice Wallenberg Foundation. It is a multinational research team composed of MIT and the Royal Swedish Institute of Technology. After four years of research, it is the latest research result in the international engineering education community. CDIO stands for Conceive, Design, Implement and operate. From the initial stage of product development to the entire process of production and operation, it allows students to learn in an active, practical, and organic way between courses [4]. The CDIO concept not only inherits and develops the concept of engineering education reform in Europe and the United States for more than 20 years, but more importantly, it systematically proposes operable capacity training, comprehensive implementation, and inspection and evaluation standards, and reforms the past talent training model and system. Besides, it strengthens the reform of practical teaching, focusing on cultivating students' engineering practical and innovation ability. Based on the CDIO engineering education model, the reform is carried out from two aspects: the practical curriculum system and teaching mode.

\subsection{Optimization of practice curriculum system}

In the early training plan for the measurement and control major, there are 4 professional practice links in basic professional skills training, production practice, comprehensive curriculum design 1 and comprehensive curriculum design 2. The 4 links are independent of each other and fail to effectively constitute an overall engineering problem.
Combining the requirements for the proportion of practice in the engineering education certification label, in the new version of the training plan, the professional practice link is divided from 4 increased to 5 , and the relationship between the whole and the part in the practice teaching system is set up as a whole. that is to say the 5 practice-links are linked vertically, and the organic connection between theory and practice is effectively constructed horizontally, as it is shown in Figure 1

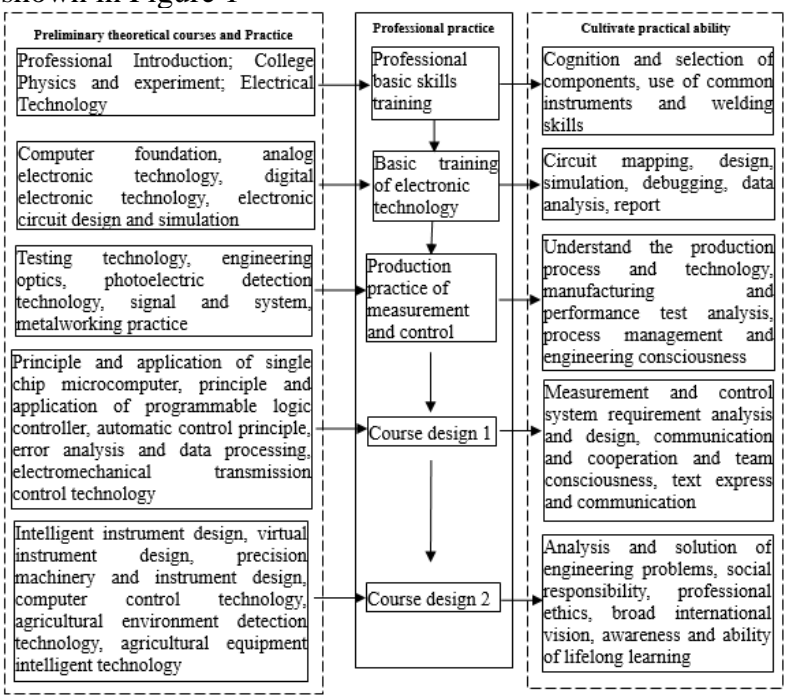

Figure 1. Practical teaching system of Measurement \& Control Technology and Instrument

\subsection{Practice teaching reform}

\subsubsection{Practice teaching model}

The reformed practical teaching mode is no longer based on traditional professional classes, but for students of the entire measurement and control major. In groups, each group of 8 to 10 people will be assigned 2 instructors. Practice forms include: visits to the practice base, project discussion and plan design, open questions, project design and implementation, mid-term inspections, on-site assessments, and results acceptance. Each practice link focuses slightly on the nature and content. For the visit of the internship base, actively explore the way of schoolenterprise cooperation. Teachers lead students to visit the internship base. The company's engineers will explain a complete project in terms of demand analysis, product design, and technology development, so that students can understand the full range of product development. process. For the school design stage, the basic requirements of the project are put forward for students, including information review, group discussion, demand analysis, scheme design and feasibility demonstration, team task division, and open question defense. 


\subsubsection{Quality monitoring of the course design process}

Under a unified schedule, each group of instructors is responsible for the guidance of the group of students, including the rational control of the team's division of labor, the demonstration of the design plan, the coordination of resources in the implementation process, the log review, and the management of safety regulations. Others, such as opening questions, on-site assessment and acceptance, and on-site defense of team members, adopt a professional and unified approach. Strictly strengthen the process assessment, and the final score is composed of the opening report, the usual assessment, the internship report, the actual design and the internship defense results. Focusing not only on the results but more on the process, the process evaluation mainly includes the forms of open questions, engineering literacy, and mid-term inspections. The result evaluation is mainly from the aspects of the quality of the work, the effect of the defense, and the quality of the design report. Among them, the design report and peacetime assessment results are given by the instructor of this group, and the question opening, mid-term inspection and design results are given by the defense committee. The assessment standards and requirements are shown in Figure 2.

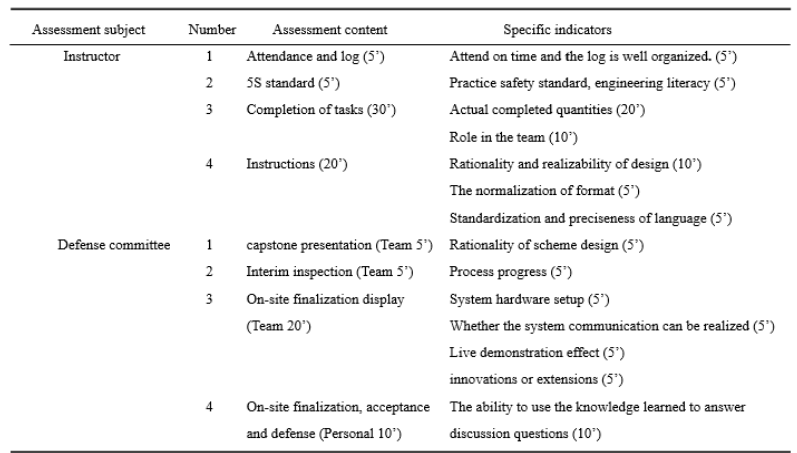

Figure 2. The grading standard of professional practice teaching of measurement \& control technology and instrument

\subsubsection{Exploration of the "Internet + practical teaching" model}

For local applied universities, practical teaching is a direct means of cultivating students' engineering application ability. However, it is often limited by limited funds and resources. There are certain limitations in the scale of school-enterprise cooperation and the breadth and depth of practical content. How to make full use of modern network resources to make up for the lack of resources in professional practice is a problem worth exploring. How to make full use of modern network resources to make up for the lack of resources in professional practice is a problem worth exploring. Use online and offline interactive integration, actively carry out the network construction of practical courses, place online teaching resources such as basic theory explanations, basic equipment operations, task development instructions and project design ideas, such as: professional teachers record lectures according to the needs of curriculum construction Video, the introduction of engineering application teaching videos recorded by some enterprise engineers, and the introduction of resources such as actual engineering case libraries, product technical manuals, etc., to achieve diversified practical course network resources. Conduct offline project organization and implementation, practical training, teacher-student interaction and other practical links, and apply the online laboratory open management system to facilitate teachers and students to carry out practical projects [5]. At the same time, online and offline integration can organically integrate into the ideological and political education of the course, comprehensively cultivate students' practical application ability and ideological and moral quality, comprehensively promote the ideological and political education of professional courses, build online ideological and political elements with "craftsman spirit" as the main line, and stimulate students' craftsman spirit and teamwork spirit.

Through online course building, it is convenient to supervise the participation of each student, and issue reminders to each backward student through statistical data. This way can eliminate the phenomenon of "sitting and waiting". It is convenient to carry out group discussion, report, stage achievement summary and process material archiving and sharing management; It can realize the transparency and fairness of process performance, and effectively stimulate students' learning motivation and enthusiasm for participation. In the Internet plus era, professional practice courses should also be taught in the context of "Internet plus", and make full use of cyber source and network means to innovate in practice teaching mode.

\section{RESULTS AND CONCLUSION}

Measurement \& control technology and instrument has the characteristics of typical interdisciplinary and strong practicality. Based on many years of practice teaching, teachers of Measurement \& control technology and instrument in Tianjin Agricultural University have carried out continuous and effective reform and Exploration on the professional practice teaching system under the guidance of CDIO Engineering Education thought. The purpose is to follow the "Fudan consensus", " Tianjin University action" and "Beijing Guide" to cultivate engineering and technical talents with engineering practice ability and innovation ability. It not only arouses the enthusiasm of the students, but also cultivates their innovative consciousness and team spirit. Graduates are generally praised by employers, creating a group of talents with strong innovation ability and adapting to the needs of social development. 


\section{ACKNOWLEDGMENT}

This work was supported by the Research and Reform Project of Undergraduate Education and Teaching in Tianjin Agricultural University (2018-A-07).

\section{REFERENCES}

[1] Ma Zhong, Shi Lei. Development and discipline construction of environmental and resource economics [J]. Teaching in Chinese universities,2018(6):30-33,9.

[2] Yan Junhong, Li Zhonghu. Research and Practice on improving the comprehensive ability of students majoring in measurement and control technology and instrument based on CDIO [J]. China modern educational equipment,2019(11):112-114.
[3] Xiong Feili, Wang Guangming, Meng Xianggui, et al. Analysis and design of practical teaching system for measurement and control technology and instrument specialty $[\mathrm{J}]$. Experimental science and technology,2017(06):141-144

[4] Wan min. research on practice teaching system reform of measurement and control specialty based on CDIO Engineering Education Mode under the background of "double first class" [J]. Education modernization, 2020(06):54-57.

[5] Liu Xuming. Practice teaching reform and practice of electrical engineering specialty for local application oriented Undergraduate Based on "Four Integration" [J]. University education,2021(06):71-73 